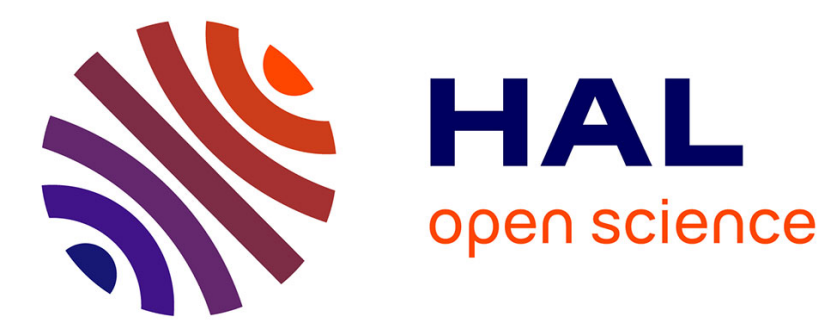

\title{
ON THE FIELD COOLED SUSCEPTIBILITY OF SUPERCONDUCTING YBaCuO SAMPLES
}

\author{
F. Celani, R. Messi, N. Sparvieri, S. Pace, A. Saggese, C. Giovannella, L.
} Fruchter, C. Chappert

\section{- To cite this version:}

F. Celani, R. Messi, N. Sparvieri, S. Pace, A. Saggese, et al.. ON THE FIELD COOLED SUSCEPTIBILITY OF SUPERCONDUCTING YBaCuO SAMPLES. Journal de Physique Colloques, 1988, 49 (C8), pp.C8-2107-C8-2108. 10.1051/jphyscol:19888947 . jpa-00229226

\section{HAL Id: jpa-00229226 https://hal.science/jpa-00229226}

Submitted on 1 Jan 1988

HAL is a multi-disciplinary open access archive for the deposit and dissemination of scientific research documents, whether they are published or not. The documents may come from teaching and research institutions in France or abroad, or from public or private research centers.
L'archive ouverte pluridisciplinaire HAL, est destinée au dépôt et à la diffusion de documents scientifiques de niveau recherche, publiés ou non, émanant des établissements d'enseignement et de recherche français ou étrangers, des laboratoires publics ou privés. 


\title{
ON THE FIELD COOLED SUSCEPTIBILITY OF SUPERCONDUCTING YBaCuO SAMPLES
}

\author{
F. Celani $\left({ }^{2}\right)$, R. Messi $\left({ }^{1}\right)$, N. Sparvieri $\left({ }^{3}\right)$, S. Pace $\left({ }^{6}\right)$, A. Saggese $\left({ }^{2}\right)$, C. Giovannella $\left({ }^{1}\right)$, \\ L. Fruchter $\left({ }^{4}\right)$ and C. Chappert $\left({ }^{5}\right)$ \\ (1) Dip. di Fisica, Universita di Roma II, Via O. Raimondo, 00173 Rome, Italy \\ ${ }^{2}$ INFN, Lab. Naz. Frascati, 00044 Frascati, Italy \\ $\left({ }^{3}\right)$ Selenia Spa, Via Tiburtina, Rome, Italy \\ (4) Physique des Solides, Bât. 510, 91705 Orsay, France \\ $\left.{ }^{5}\right)$ Institut d'Electronique Fondamentale, Bât. 220, 91405 Orsay, France \\ ( $\left.{ }^{6}\right)$ Dip. di Fisica, Universitā di Salerno, 84100 Salerno, Italy.
}

\begin{abstract}
Using a SQUID magnetometer, we have studied the magnetization of different sampls of high $T_{\mathrm{c}}$ sintered superconductors in field cooled (FC) conditions. Depending on the sample, very different trends in the variation of the saturation value of the FC magnetization with the field have been observed; in particular for good samples it increases progressively with decreasing $H$. We ascribe the difference in behaviour to different strengths of coupling between grains, depending on the preparation conditions. Data obtained by complementary techniques support this explanation.
\end{abstract}

SQUID magnetometry is a unique tool for investigating the low field properties of the disordered junctions system existing in both sintered pellets and "single crystals" of YBCO and other superconducting oxides. In a zero field cooling procedure, the sample is first cooled in zero field $(<0.2-0.5 \mathrm{mOe})$ and then, after the measuring field is applied, is warmed slowly up to a temperature well above that for complete transition to the normal state, while the ZFC magnetization is recorded. As a final step of the experiment, the sample is cooled down slowly in the measuring field and the low $T(5 \mathrm{~K})$ limit of the field cooling (FC) magnetization measured. ZFC results have been recently used [1] to describe the critical behaviour, under a magnetic field, of the 3D disordered junctions system (JJ) and will not be discussed here any further. The FC data have been subjected to several interpretations. First, they have been thought to give a measure of the Meiss-

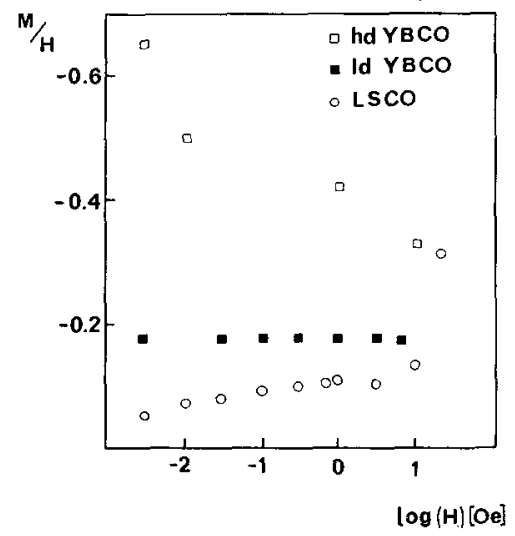

Fig. 1. - Low temperature limit values of the ratio $M / H$ (where $M$ is the measured magnetization and $H$ is the cooling field) plotted against $H$ for: samples of $\mathrm{LSCO}$, standard (ld) TBCO and dense (hd) YBCO. ner effect; and this has been clearly shown not to be the case [2]; subsequently, they have been considered as a support to the glassy state model, and some months later to a much more classical flux pinning model [3] by which it should be possible to explain an observed $H^{1 / 3}$ dependence of the low $T$ limit of the FC magnetization with the field. The experimental situation, however, is not simple and, depending on the sample preparation, very different trends are observed (see Fig. 1). In fact in a same field range (in our case $3 \mathrm{mOe}-20 \mathrm{Oe}$ ), samples with poorly connected grains, like the "old" LSCO ( $60 \%$ dense), show a slow increase of the low $T$ limit of the FC magnetization up to a critical field for which an abrupt transition occurs; standard YBCO samples (60\%-70\% dense), on the other hand, show only a flat plateau, while very dense samples (90\% -95\%) produced by a modified pyrolitique method are characterized by an increase of the saturation value of the magnetization with the decrease of the field (but not as $H^{1 / 3}$ ). These apparently very different behaviours can find a common explanation in the existence of the Josephson junctions system and can be considered to mirror the evolution of its connectivity with the field. In poorly connected samples, during the FC procedure, some junctions reconstruct and trap fluxons in those intergranular zones for which the Josephson coupling,

$$
J_{i j}=\Delta(T) / R_{i j} \operatorname{tg} h\left[\Delta(T) / 2 R_{i j} T\right]
$$

is weaker because of the bigger distance between grains, i.e. because of the larger normal state resistance $R_{i j}$. As long as the field is greater than the critical value at which there no longer exists a connected network, $J_{c}$ is on average zero, the junctions system breaks down and does not trap fluxons any longer (or only does so poorly). As the quality of the sample becomes better (higher density), the flux is expelled more and more from the intergranular volume and the $\mathrm{FC}$ 
magnetization level increases. Of course, if we were able in the case of the dense sample to use higher fields we should have been able to observe the evolution of the JJ system untill its breaking up like in the ISCO case. The above picture is strongly supported by figure 2 in which we show the low field hysteresis loops (measured by a Vibrating Sample Magnetometer, VSM [4]) of the three samples described above (Figs. 2a and 2b) a sketch of the $M / H$ behaviour (continuous line) deducible from the hysteresis loop, once that the diamagnetic contribution of the single grains is subtracted. In a FC process, fluxons are trapped in the junctions and the low $T$ limit of the FC susceptibility is given by the sum of the lower part of the $M / H$ curve, due mainly to screening currents, plus the upper part of the $M / H$ curve, due mainly to trapped fluxons. The sum is represented schematically by the dashed line. When the junction system breaks up the low $T$ limit of the FC susceptibility becomes equal to the ZFC one, and comes from the diamagnetic contribution of currents looping on the surface of the isolated grains (dotted line of Fig. 2a). The different extensions of the hysteresis loops of the samples allows us to move in the SQUID experiments along the dashed line of figure $2 \mathrm{~b}$. In the case of the LSCO sample the loop closes at about $10 \mathrm{G}$, justifing the breaking of the JJ system shown in figure 1. The loop of the $60 \%$ dense YBCO closes at about $45 \mathrm{G}$, justifing also the plateau observed in figure 1 . The increase in the level of the FC magnetization observed by SQUID in the case of the dense sample, however, is not directly deducible from its hysteresis loop because of the impossibility in the VMS experiments to screen perfectly the earth's magnetic field. However, it is worthwhile stressing that in going from the LSCO sample to the very dense YBCO sample, the intensity of the magnetization, measured by VMS at constant field, increases continuously and the hysteresis loop extends more and more, in agreement with the $M / H$ ratio shown in figure 1. Further support to this picture is also given by the shape of the resistivity transition shown in figure 3 (the measurements have been done on plaquettes of the same geometrical dimensions using $1 \mathrm{~mA}$ as an excitation current). The long tail visible near the offset temperature is related to the existence of the junctions [5], and it is very evident that in the less dense sample there exists an higher density of junctions with a wider spread of coupling strengths. Moreover the denser YBCO shows, as expected from [1], a lower $R_{i j}$. Finally because the divergence between the FC and the ZFC magnetizations have been often related to the superconducting glass, SuG, problem we think that it is worthwhile stressing that because the FC state is what we call a "dirty" state of non-equilibrium with fluxons trapped all over, its evolution with the temperature cannot give useful informations on the value of the SuG critical exponents [6].

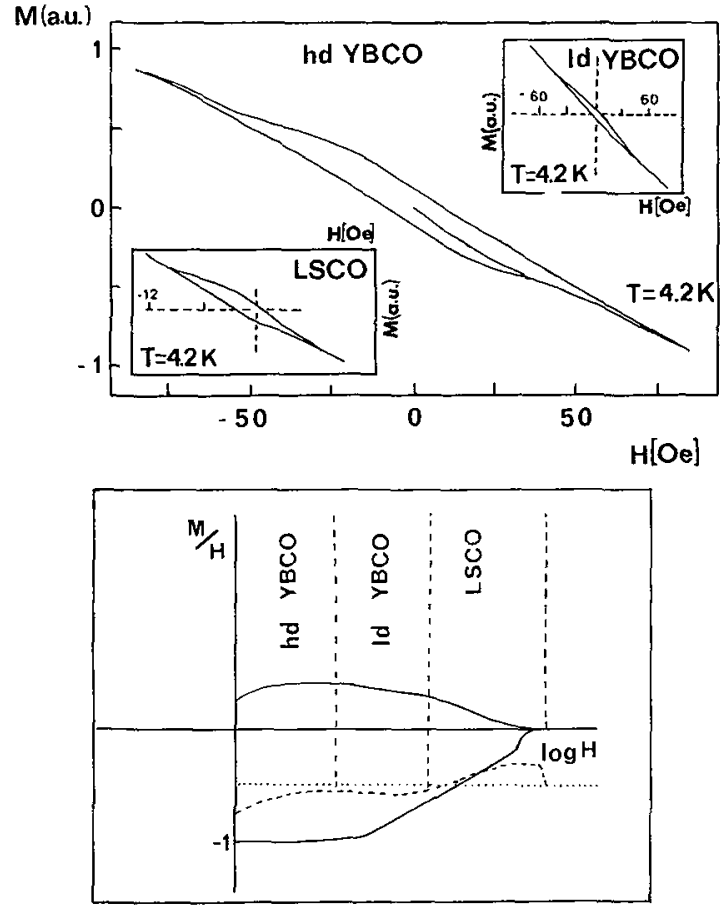

Fig. 2. - (a) Low field hysteresis loops for samples as in figure 1. (b) Schematic reconstruction of the $M / H$ behaviour from an hysteresis loop.

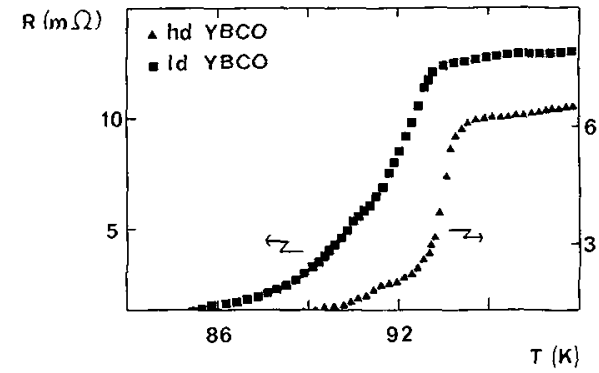

Fig. 3. - Resistive transition for the $\mathrm{ld} \mathrm{YBCO}$ and the hd YBCO samples.

[1] Giovannella, C., Chappert, C., Beauvillain, P., Europhys. Lett. 5 (1988) 535.

[2] Giovannella, C., Chappert, C., Beauvillain, P., Collin, G., Int. J. Mod. Phys. 1 (1987) 1011.

[3] Krusin-Elbaum, L., Malozemoff, A. P., Yeshrun, Y., Cronemeyer, D. C., Holtzberg, ${ }^{-F}$., Physica $C$ 153 (188) 1469.

[4] Senoussi, S., Oussena, M., Ribault, M., Collin, G., Phys. Rev. B 36 (1987) 4003.

[5] Carolan, J. F., Hardy, W. N., Krahn, R., Brewer, J. H., Thompson, J. H., Chaklader, A. C. D., Solidi State Comm. 64 (1987) 717;

Dubson, M. A., Herbert, S. T., Calabrese, J. J., Harris, D. C., Patton, B. R., Garland, J. C., Phys. Rev. Lett. 60 (1987) 1061.

[6] Giovannella, C., Universalities in Condensed Matter Physics, Ed. R. Jullien and L. Peliti (Springer Verlag) in print. 